\title{
ANÁLISE BIBLIOMÉTRICA DA PRODUÇÃO CIENTÍFICA BRASILEIRA E INTERNACIONAL SOBRE REAÇÃO ÁLCALI-AGREGADO (RAA)
}

\author{
EMANUELLE ALVES ARAÚJO SILVA \\ Acadêmica de Eng. Civil \\ Universidade Estadual Vale do Acaraú \\ Ceará; Brasil \\ manuh_araujo13@hotmail.com
}

\author{
KELVYA MARIA DE VASCONCELOS MOREIRA \\ PPG Eng. e Ciência de Materiais/UFC \\ Prof ${ }^{a}$ Eng. Civil/UVA \\ Ceará; Brasil \\ kelvyamoreira@gmail.com
}

\author{
ÊNIO PONTES DE DEUS \\ PPG Eng. e Ciência de Materiais/UFC \\ Ceará; Brasil \\ epontes@ufc.br
}

\author{
ANTÔNIO EDUARDO BEZERRA CABRAL \\ PPG Eng. Civil/UFC \\ Ceará; Brasil \\ eduardo.cabral@ufc.br
}

\section{RESUMO}

A reação álcali-agregado é uma manifestação patológica endógena de gravidade elevada que pode ocorrer em compósitos cimentícios submetidos a determinadas condições químicas, de temperatura e de umidade; e o conhecimento da ocorrência desta anomalia em obras brasileiras pode ser considerado relativamente recente. Assim, o estudo em questão trata da análise bibliométrica da produção científica brasileira e internacional sobre tal reação com o propósito de identificar possíveis lacunas no conhecimento do tema a fim de nortear novas pesquisas e fortalecer o arcabouço teórico. Nesse contexto, utilizou-se a metodologia Proknow-C para conhecer os indicadores bibliométricos a partir da análise de artigos científicos publicados em periódicos e anais de congressos indexados nas bases de dados SciELO, Scopus e ScienceDirect, considerando o interstício de 2004 a 2019.

Palavras-chave: reação álcali-sílica, bibliometria, lacuna no conhecimento.

\section{ABSTRACT}

The alkali-aggregate reaction is an endogenous pathological manifestation of high severity that can occur in cementitious composites subjected to certain chemical, temperature and humidity conditions; and knowledge of the occurrence of this anomaly in Brazilian works can be considered relatively recent. Thus, the study in question deals with the bibliometric analysis of the Brazilian and international scientific production about such reaction with the purpose of identifying possible gaps in the knowledge of the subject in order to guide new research and strengthen the theoretical framework. In this context, we used the Proknow-C methodology to know the bibliometric indicators from the analysis of scientific articles published in journals and conferences indexed in the SciELO, Scopus and ScienceDirect databases, considering the period from 2004 to 2019.

Keywords: alkali-silica reaction, bibliometrics, knowledge gap.

\section{INTRODUÇÃO}

A reação álcali-agregado (RAA) é um tipo de manifestação patológica endógena de gravidade elevada que pode ocorrer em compósitos cimentícios submetidos a determinadas condições químicas, de temperatura e de umidade. Basicamente, ela se desenvolve entre os constituintes reativos dos agregados e íons alcalinos e hidroxilas presentes na solução intersticial da pasta de cimento. O produto da reação é um gel geralmente expansivo que passa a ocupar os poros do compósito cimentício.

Para a ocorrência da RAA são necessárias três condições: (1) elevado teor de álcalis (notadamente sódio e potássio), que pode ser fornecido pelo cimento (principal), aditivos químicos, água de mistura, adições minerais ou por fontes externas, como as águas industriais e marinhas; (2) agregado potencialmente reativo, caracterizado como aquele que possui fases mineralógicas, em geral silicosas, sensíveis ao meio alcalino, como opala, tridimita, cristobalita, vidro 
vulcânico, calcedônia, entre outros minerais; e (3) elevada umidade (cerca de $80 \%$ a 85\%) para permitir a migração dos íons e espécies reativas, além de atuar já no produto da reação formado provocando expansões.

Há três tipos de RAA: reação álcali-carbonato (RAC), que ocorre entre os hidróxidos alcalinos e certos agregados calcários dolomíticos; reação álcali-sílica (RAS), que ocorre entre os hidróxidos alcalinos e certos agregados silicosos, quando constituídos de sílica amorfa, mal cristalizada ou microcristalina; e reação álcali-silicato, considerada, atualmente, como um tipo lento de reação álcali-sílica, cuja diferença principal entre esta e a RAS está no fato de que os agregados reativos da reação álcali-silicato não serem formados de sílica livre, mas de silicatos variados (filossilicatos ou tectossilicatos, sãos ou alterados) (HASPARYK, 2011; OLLIVIER; VICHOT, 2014; ABNT NBR 15577-1:2018).

O que se tem observado, em nível de Brasil, é que o número de casos identificados de RAS nas estruturas de concreto tem aumentado, decorrente da maior compreensão da manifestação patológica em si pela comunidade científica e/ou pela maior preocupação do setor pericial/diagnóstico com as consequências. Além disso, lamentavelmente, quando os casos são identificados nas estruturas em serviço, em geral, elas já se encontram em avançado desenvolvimento da reação, o que dificulta o tratamento.

Vários estudos científicos sobre a reação álcali-agregado, como um todo, têm sido desenvolvidos para se obter uma maior compreensão do seu mecanismo de atuação e, a partir daí, poder propor medidas de mitigação ou mesmo eliminação de tal manifestação patológica. Assim, o trabalho em questão visa fazer um apanhado dos estudos mais relevantes, em nível de Brasil a princípio, usando o Proknow-C, que será explicitado posteriormente, como ferramenta de seleção.

A bibliometria, portanto, é um método de análise quantitativa para a pesquisa científica. Os dados elaborados por meio dos estudos bibliométricos mensuram a contribuição do conhecimento científico derivado das publicações em determinadas áreas. Os indicadores de produção são úteis para o planejamento e a execução de políticas públicas, e para o conhecimento da comunidade científica sobre o sistema em que está inserida (SOARES et al, 2015).

\section{CONCEITO}

\subsection{Reação Álcali-Agregado (RAA)}

\subsubsection{Início dos estudos da RAA no Brasil}

O marco inicial para que o estudo fosse mais enfatizado no país foi baseado no ano do colapso do Edifício Areia Branca, localizado na zona sul da Região Metropolitana do Recife, Pernambuco, Brasil. Tal colapso, ocorrido em 14 de outubro de 2004, provocou a morte de 4 pessoas e gerou uma movimentação do meio técnico brasileiro para identificar as causas do ocorrido. Ainda que muitos tenham especulado como causa principal o fenômeno da RAA, no laudo emitido pelo Conselho Regional de Engenharia e Agronomia (CREA) da cidade de Pernambuco consta a grande incidência de vícios construtivos durante a execução da obra. No entanto, é consenso que o problema foi agravado pela ocorrência da RAA. Este fato gerou um alerta em moradores que decidiram por efetuar vistorias nas fundações de obras prediais das Regiões Metropolitanas das cidades de Olinda e Recife (PE), tendo como resultado a constatação de cerca de 20 edifícios comerciais e residenciais com suas fundações comprometidas pela RAA (FIGUEIRÔA; ANDRADE, 2007).

Este fato lamentável serviu de alerta para que, em 2005, profissionais e especialistas de diversas áreas se unissem para a implantação de uma comissão de estudos e discussões para a elaboração de norma técnica brasileira relativa ao tema e outras publicações com base em documentos de instituições de pesquisa internacionais a fim de nortear melhor o meio técnico brasileiro acerca do problema. É notório que esses estudos já eram conhecidos em outros países mas esse fato alavancou o conhecimento da comunidade científica brasileira em relação ao tema.

\subsubsection{Reação Álcali-Sílica (RAS)}

Dentre os três tipos de RAA mencionados, tem-se que a RAS é a mais estudada pelo meio científico dada a sua maior ocorrência a nível mundial, sua complexidade e gravidade. Quanto à ocorrência da RAS, era de entendimento do meio técnico que as obras mais suscetíveis seriam aquelas de grande volume de compósito cimentício, notadamente o concreto, e que tivessem mais acesso à elevada umidade, proveniente do próprio meio interno ou externo, tais como 
barragens, pilares de pontes, usinas hidrelétricas e bases de geradores de usinas de energia eólica; no entanto, atualmente, já se tem histórico de graves casos de ocorrência da RAS em estruturas menores, como pavimentos e fundações de edifícios comerciais e residenciais.

\subsection{Utilização do Proknow-C}

O método de revisão sistemática conhecido como Proknow-C (Knowledge Development Process - Constructivist) foi desenvolvido para a seleção dos artigos mais relevantes sobre o tema de interesse do pesquisador, sendo idealizado para possibilitar a realização de uma análise a fim de averiguar os principais trabalhos, autores e periódicos que publicaram sobre o tema de interesse. Além da seleção dos artigos para compor um referencial teórico, o processo evidencia também a possibilidade de uma análise bibliométrica, a qual hierarquiza os periódicos que mais se destacam quanto a publicações sobre o tema. Através do ProKnow-C é possível selecionar e evidenciar artigos, autores e periódicos na área e construir, desta maneira, o arcabouço teórico dos trabalhos acadêmicos e científicos mais relevantes para a pesquisa de interesse (LACERDA; ELSSLIN; ELSSLIN, 2012).

A bibliometria possibilita a observação do estado da ciência e tecnologia por meio de toda a produção científica registrada em um repositório de dados. É um método que permite situar um país em relação ao mundo, uma instituição em relação a um país, e cientistas individuais em relação às próprias comunidades científicas. Baseia-se na contagem de artigos científicos, patentes e citações. Dependendo da finalidade do estudo bibliométrico, os dados podem ser tanto o texto que compõe a publicação como os elementos presentes em registros sobre publicações extraídos de base de dados bibliográficos, como nome de autores, título, fonte, idioma, palavra-chave, classificação e citações (RAO, 1986; ZHU et al., 1999). A bibliometria pode auxiliar na identificação de tendências de crescimento do conhecimento em determinada disciplina, dispersão e obsolescências de campos científicos, autores e instituições mais produtivos, e periódicos mais utilizados na divulgação de pesquisas em determinada área do conhecimento (SOARES et al, 2015).

\section{METODOLOGIA}

Para a construção desse portfólio bibliográfico foi utilizado o método de revisão sistemática conhecido como ProknowC, desenvolvido e patenteado por Ensslin et al. (2010), com 8 passos a serem seguidos:

1 - Definir as bases de dados pertinentes;

2 - Estabelecer os critérios de busca (filtros);

3 - Definir a metodologia de construção do arcabouço bibliográfico;

4 - Definir o(s) algoritmo(s) de busca;

5 - Realizar a busca, em todas as bases de dados, usando o(s) algoritmo(s);

6 - Expor os indicadores bibliométricos dos artigos selecionados;

7 - Montar gráficos e tabelas com os indicadores bibliométricos;

8 - Efetuar análise crítica dos resultados obtidos.

Para a realização da pesquisa optou-se pela utilização de 03 bases de dados, à princípio: (1) SciELO, (2) Scopus e (3) ScienceDirect. Diante disso, com o decorrer da pesquisa foram encontrados artigos relevantes sobre o tema em questão apenas nas bases (1) e (3). Como algoritmos de busca foram utilizados os seguintes termos: "reação álcali-agregado", "reação álcali-sílica", "agregado reativo" e "álcalis do cimento". É importante destacar que, até a finalização deste artigo, o portfólio bibliográfico foi construído apenas com publicações de acesso livre nas bases de dados, onde as palavras-chave mais citadas foram inseridas nos sites, com um total de 15 artigos encontrados. Ressalta-se, no entanto, que esta pesquisa tem um cunho mais amplo. Diante disso, os indicadores bibliométricos utilizados para a análise foram: índice, assunto principal, periódico, ano do artigo, país do periódico, país da pesquisa, autor(es), instituição(ões), tipo de reação álcali-agregado e palavras-chave.

\section{RESULTADOS DA PESQUISA}

Nas duas bases de dados foram necessários colocar índices para identificar os artigos com maior clareza e, inicialmente, foram priorizados tema, periódico e ano de cada artigo. A Tabela 1 expõe os artigos encontrados na plataforma Scielo e a Tabela 2 aqueles encontrados na plataforma ScienceDirect. 
Tabela 1 - Dados dos artigos encontrados na plataforma Scielo.

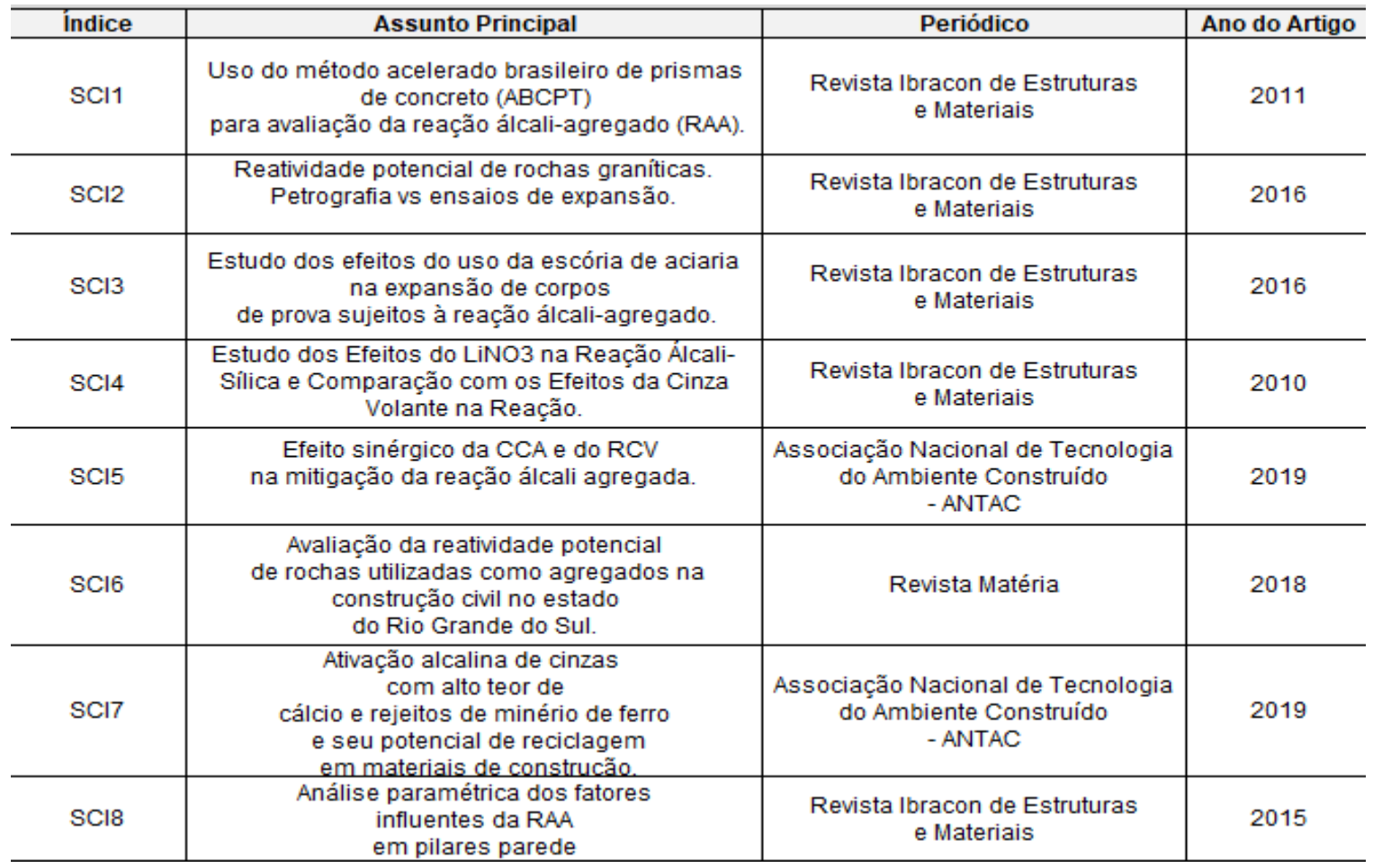

Tabela 2 - Dados dos artigos encontrados na plataforma Science Direct.

\begin{tabular}{|c|c|c|c|}
\hline Índice & Assunto Principal & Periódico & Ano do Artigo \\
\hline SD1 & $\begin{array}{c}\text { Testar evidências do papel essencial } \\
\text { dos íons } \mathrm{OH} \text { - nas reações alcalino- } \\
\text { silício. }\end{array}$ & $\begin{array}{l}\text { Cement and } \\
\text { Concrete } \\
\text { Research }\end{array}$ & 1993 \\
\hline SD2 & $\begin{array}{c}\text { Suporte da modelagem à experiência } \\
\text { em infraestruturas atendidas } \\
\text { pela reação alcalina-silício. }\end{array}$ & $\begin{array}{l}\text { Mécanique \& } \\
\text { Industries }\end{array}$ & 2003 \\
\hline SD3 & $\begin{array}{c}\text { Sulfato de metal alcalino } \\
\text { - um fator comum à reação de } \\
\text { agregados alcalinos e ao ataque de } \\
\text { sulfato no concreto. }\end{array}$ & $\begin{array}{l}\text { Cement and } \\
\text { Concrete } \\
\text { Research }\end{array}$ & 1980 \\
\hline SD4 & $\begin{array}{l}\text { Medição experimental da cinética de } \\
\text { formação de um gel de sílica-cálcio, } \\
\text { produto da reação álcali-sillica. }\end{array}$ & $\begin{array}{l}\text { Cement and } \\
\text { Concrete } \\
\text { Research }\end{array}$ & 1997 \\
\hline SD5 & $\begin{array}{c}\text { Influência do cal nas reações entre } \\
\text { álcalis e agregados de silico- } \\
\text { aluminato. }\end{array}$ & $\begin{array}{l}\text { Cement and } \\
\text { Concrete } \\
\text { Research }\end{array}$ & 1991 \\
\hline SD6 & $\begin{array}{c}\text { Abordagem termodinâmica e cinética } \\
\text { da reação álcali-sílica. Parte } 2 \text { : } \\
\text { Experiência. }\end{array}$ & $\begin{array}{l}\text { Cement and } \\
\text { Concrete } \\
\text { Research }\end{array}$ & 1993 \\
\hline SD7 & $\begin{array}{c}\text { A concentração de álcalis por migração } \\
\text { de umidade no concreto - } \\
\text { um fator que influencia a reação do } \\
\text { agregado alcalino }\end{array}$ & $\begin{array}{l}\text { Cement and } \\
\text { Concrete } \\
\text { Research }\end{array}$ & 1979 \\
\hline
\end{tabular}

As Tabelas 1 e 2 mostram que, em periódicos internacionais, o estudo sobre RAA vem sendo destaque há muito tempo (com datas de 1979), mas que, em periódicos brasileiros, a reação vem sendo relatada mais recentemente, mostrando que a data de corte inicial definida (ano de 2004 quando ocorreu o colapso do Edifício Areia Branca, em Pernambuco) é coerente para o propósito da pesquisa. Este cenário faz crer que as reações álcali-agregado, no Brasil, não eram 
enfatizadas por não serem visíveis a curto prazo e sabe-se que, no ramo da Engenharia Civil, por vezes, é valorizada a entrega das obras no prazo e não a durabilidade delas ao longo dos anos. Em um evento internacional de concreto, denominado Concrete Show 2019, foi apresentado que 60\% das obras viabilizadas no Brasil não realizam testes de laboratório para prevenir a RAA, então, com isso, o número de estruturas jovens, com idade entre 5 a 10 anos, já manifestam essa anomalia (HOLANDA, 2019).

Ainda pelas Tabelas 1 e 2 é notável avaliar que, no Brasil, as pesquisas sobre RAA apresentaram mais relevância a partir de 2010 e se mantêm até os dias atuais. Nesse contexto, pode-se inferir que, no país, os estudos se intensificaram devido à comissão de estudos montada em 2005 para a elaboração de normas técnicas sobre o tema e possíveis soluções.

A Figura 1 ilustra as nacionalidades dos periódicos elencados nas Tabelas 1 e 2; enquanto que a Figura 2 ilustra as nacionalidades de origem das pesquisas.

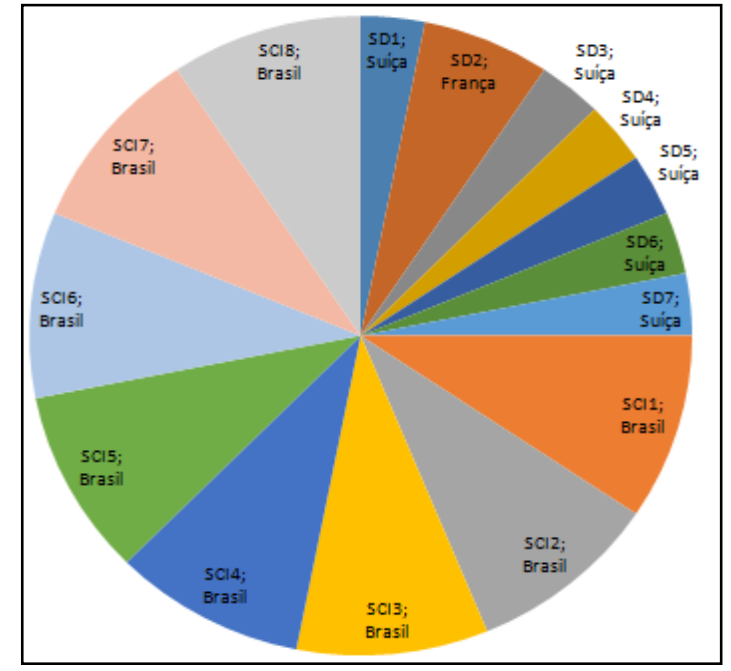

Figura 1 - Distribuição de artigos por nacionalidade dos periódicos.

Pela Figura 1 é possível perceber pouca variedade entre os países dos periódicos que contêm os artigos estudados. A Suíça representa o periódico "Cement and Concrete Research", a França representa o "Mécanique \& Industries" e, por fim, no Brasil representa os periódicos "Revista Ibracon de Estruturas e Materiais", "Associação Nacional de Tecnologia do Ambiente Construído" e "Revista Matéria".

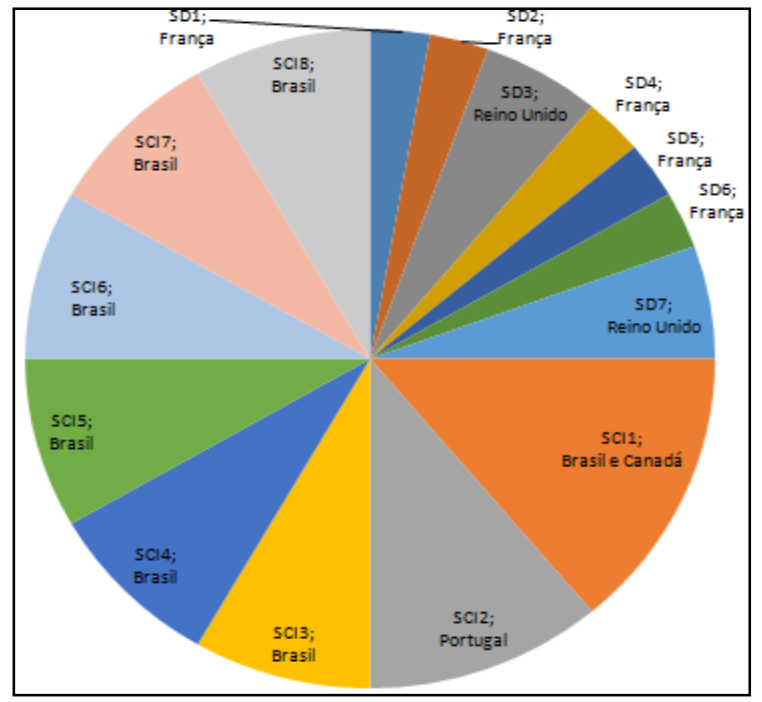

Figura 2 - Distribuição de artigos por nacionalidade da pesquisa. 
Com base na Figura 2, nota-se que as pesquisas sobre o assunto eram frequentes no continente europeu e, com o passar dos anos, as pesquisas brasileiras também ganharam destaque e notoriedade.

As Tabelas 3 e 4 detalham alguns dados dos artigos, como: autoria, instituição onde a pesquisa foi desenvolvida e o tipo de RAA estudado.

Tabela 3 - Especificações dos artigos encontrados na plataforma Scielo.

\begin{tabular}{|c|c|c|c|}
\hline Índice & Autores & Instituições & Tipo de RAA \\
\hline $\mathrm{SCl} 1$ & $\begin{array}{l}\text { L. SANCHEZ; } \\
\text { S.C. KUPERMAN; } \\
\text { P.HELENE. }\end{array}$ & $\begin{array}{l}\text { Universidade de São Paulo; } \\
\text { Universidade Laval. }\end{array}$ & RAS \\
\hline $\mathrm{SCl} 2$ & $\begin{array}{l}\text { V. RAMOS; FERNANDES; A. S. SILVA; D. } \\
\text { SOARES; F. NORONHA. }\end{array}$ & $\begin{array}{l}\text { Universidade de Porto; } \\
\text { Universidade de Lisboa. }\end{array}$ & RAS \\
\hline $\mathrm{SCl} 3$ & $\begin{array}{l}\text { L. SOUZA; } \\
\text { E. R. ZOLETT; } \\
\text { R. CARRAZEDO. }\end{array}$ & $\begin{array}{c}\text { Universidade Tecnológica Federal do } \\
\text { Paraná; } \\
\text { Universidade de São Paulo. }\end{array}$ & RAS \\
\hline $\mathrm{SCl} 4$ & $\begin{array}{l}\text { D. J.F. SILVA; } \\
\text { V.FAZZAN; } \\
\text { C. F. FIORITI; }\end{array}$ & Universidade Estadual Paulista & RAS \\
\hline SCl5 & $\begin{array}{c}\text { Patrícia Guillante; } \\
\text { Aguida Gomes de Abreu; } \\
\text { Marlova Piva Kulakowski; } \\
\text { Maurício Mancio; } \\
\text { Claudio de Souza. Kazmierczak. }\end{array}$ & $\begin{array}{l}\text { Universidade do Vale } \\
\text { do Rio dos Sinos }\end{array}$ & $\begin{array}{c}\text { RAA } \\
\text { NÃO ESPECIFICADO }\end{array}$ \\
\hline $\mathrm{SCl} 6$ & $\begin{array}{c}\text { Fernanda Macedo Pereira; } \\
\text { Paulo César Pereira das Neves; } \\
\text { Denise Maria Lenz; } \\
\text { José Carlos Krause de Verney. }\end{array}$ & $\begin{array}{l}\text { Universidade Luterana } \\
\text { do Brasil }\end{array}$ & $\begin{array}{c}\text { RAA } \\
\text { NÃO ESPECIFICADO }\end{array}$ \\
\hline $\mathrm{SCl} 7$ & $\begin{array}{c}\text { Augusto César da Silva } \\
\text { Bezerra; } \\
\text { Sâmara França; } \\
\text { Luciano Fernandes de Magalhães; } \\
\text { Maria Cristina Ramos de Carvalho. }\end{array}$ & $\begin{array}{l}\text { Centro Federal de Educação } \\
\text { Tecnológica de Minas Gerais }\end{array}$ & $\begin{array}{c}\text { RAA } \\
\text { NÃO ESPECIFICADO }\end{array}$ \\
\hline $\mathrm{SCl} 8$ & $\begin{array}{l}\text { E. L. MADUREIRA; } \\
\text { E. C. RODRIGUES. }\end{array}$ & $\begin{array}{l}\text { Universidade Federal do } \\
\text { Rio Grande do Norte }\end{array}$ & $\begin{array}{c}\text { RAA } \\
\text { NÃO ESPECIFICADO }\end{array}$ \\
\hline
\end{tabular}

Tabela 4 - Especificações dos artigos encontrados na plataforma Science Direct.

\begin{tabular}{|c|c|c|c|}
\hline Índice & Autores & Instituições & Tipo de RAA \\
\hline SD1 & $\begin{array}{l}\text { W. Prince; } \\
\text { R. Perami. }\end{array}$ & $\begin{array}{c}\text { Universidade Paul } \\
\text { Sabatier }\end{array}$ & RAS \\
\hline $\mathrm{SD} 2$ & $\begin{array}{c}\text { Kefei Li; } \\
\text { Bruno Capra. }\end{array}$ & $\begin{array}{c}\text { Universidade de } \\
\text { Tsinghua; } \\
\text { Universidade Paris-Est } \\
\text { Marne-la-Vallée. }\end{array}$ & RAS \\
\hline SD3 & $\begin{array}{l}\text { K. Pettifer; } \\
\text { P.J. Nixon. }\end{array}$ & $\begin{array}{c}\text { Estabelecimento de } \\
\text { pesquisa de construção }\end{array}$ & $\begin{array}{c}\text { RAA } \\
\text { NÃO } \\
\text { ESPECIFICADO }\end{array}$ \\
\hline SD4 & $\begin{array}{l}\text { J. Lombardi; } \\
\text { P. Massard; } \\
\text { A. Perruchot, }\end{array}$ & Universidade Paris-Sud; & RAS \\
\hline SD5 & $\begin{array}{l}\text { William Prince; } \\
\text { René Perami. }\end{array}$ & $\begin{array}{c}\text { Universidade Paul } \\
\text { Sabatier }\end{array}$ & RAS \\
\hline SD6 & $\begin{array}{l}\text { Roger Dron; } \\
\text { Françoise Brivot. }\end{array}$ & $\begin{array}{l}\text { Laboratório Central } \\
\text { Ponts Et Chaussees }\end{array}$ & RAS \\
\hline $\mathrm{SD} 7$ & $\begin{array}{l}\text { P.J.Nixon DIC PhD; } \\
\text { R.J.Collins MA PhD; } \\
\text { P.L.Rayment MSc. }\end{array}$ & $\begin{array}{c}\text { Estabelecimento de } \\
\text { pesquisa de construção }\end{array}$ & $\begin{array}{c}\text { RAA } \\
\text { NÃO } \\
\text { ESPECIFICADO }\end{array}$ \\
\hline
\end{tabular}


Analisando as Tabelas 3 e 4 percebe-se que há diversidade nas instituições de desenvolvimento das pesquisas, indicando uma distribuição relevante na aplicação do conhecimento sobre a RAA, ainda que haja a necessidade de se conhecer mais a miúde as variáveis que interferem nesta reação.

Em relação ao tipo de reação estudada em cada pesquisa, aquelas que foram especificadas ( 9 pesquisas) referem-se apenas à reação álcali-sílica, provavelmente por ser o tipo de reação com maior ocorrência nas obras, denotando maior interesse na tentativa de conhecer melhor sua forma de ação e, assim, estudar maneiras de saná-la ou controlá-la, corroborando com o que já foi exposto anteriomente.

A Figura 3 apresenta as regiões geográficas onde as pesquisas brasileiras foram desenvolvidas.

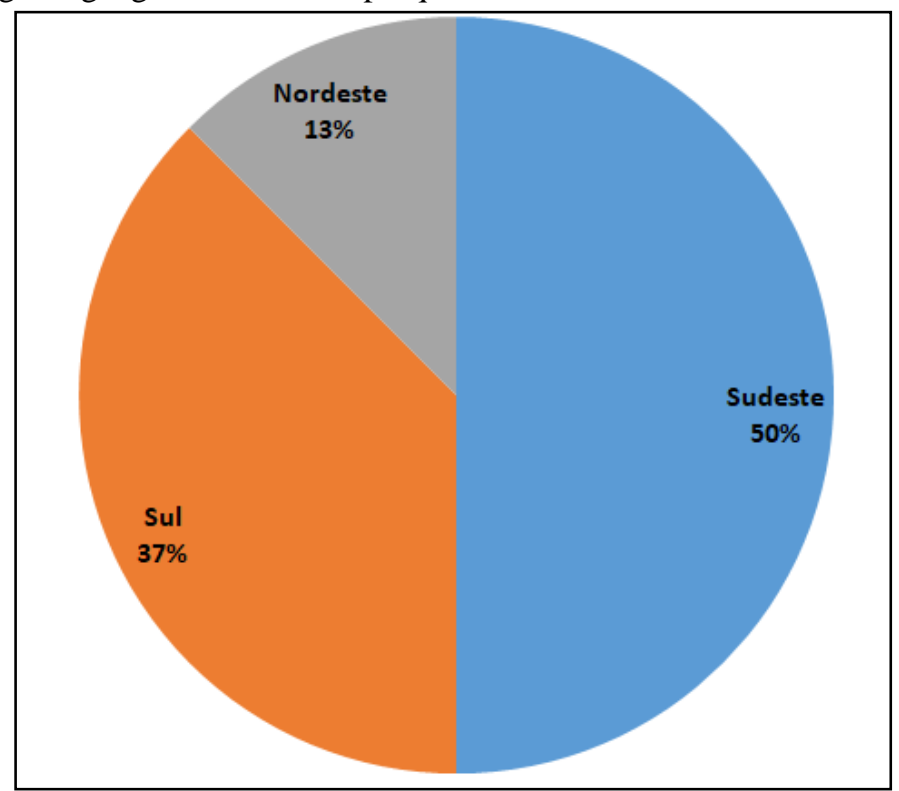

Figura 3 - Regiões do Brasil onde as pesquisas da plataforma Scielo foram produzidas.

De acordo com a Figura 3, nota-se que as pesquisas dos artigos brasileiros se concentraram mais nas regiões Sudeste e Sul do país, mesmo com o acontecimento da ruína de um prédio por reação álcali-agregado ser reconhecido na região Nordeste. Este fato não indica que não haja a ocorrência do fenômeno nas demais regiões geográficas do Brasil, mas sim que possa haver uma carência na exploração do assunto.

Fez-se, ainda, um apanhado das palavras-chave indicadas no resumo de cada artigo analisado, pois se entende que tais palavras servem para indicar o assunto principal do texto. A Tabela 5 elenca todas as palavras-chave utilizadas bem como a quantidade em que aparecem.

Com base na Tabela 5 percebe-se que a palavra-chave mais utilizada foi "reação álcali-agregado"; apenas 2 artigos mencionaram diretamente a "reação álcali-sílica", ainda que o tipo de reação mais estudado tenha sido a RAS, conforme já especificado nas Tabelas 3 e 4. Isso demonstra que as palavras-chave nem sempre foram utilizadas para indicar a abordagem principal do artigo, mas sim foram mais generalistas, o que dificulta a definição do provável leitor sobre o interesse no artigo.

Também pela Tabela 5 vê-se que há uma variedade de materiais pesquisados com o propósito de mitigar ou mesmo evitar a RAA, tais como pozolanas e escórias. Este fato é bastante positivo pois indica a preocupação em se estudar formas de mitigar tal anomalia, e não somente conhecer seu mecanismo de ação, o que está relacionado diretamente com a durabilidade das obras. Por outro lado, pouco ainda se tem trabalhado sobre modelagem da reação, o que, de certa forma, é compreensível por se tratar de um tema ainda não completamente conhecido. Também, nota-se que há muitas pesquisas voltadas ao conhecimento da reatividade de certas rochas utilizadas como agregados. Isto pode ser explicado pelo fato de que, a nível de Brasil, trabalhava-se como se suas rochas fossem preponderantemente inertes. 
Tabela 5 - Palavras-chave encontradas nos artigos analisados.

\begin{tabular}{c|c|c|c}
\hline reação álcali-agregado & 6 & agregados & 1 \\
\hline reação álcali-sílica & 2 & concreto & 1 \\
\hline $\begin{array}{c}\text { método de prismas de concreto (CPT) } \\
\text { método acelerado brasileiro } \\
\text { de prismas de concreto } \\
\text { (ABCPT) }\end{array}$ & 1 & caracterização petrográfica & 1 \\
\hline métodos de ensaio & 1 & ativação alcalina & 1 \\
\hline granito & & & 1 \\
\hline petrografia & 1 & cinzas com alto teor de cálcio & 1 \\
\hline ensaios de expansão & 1 & rejeito de minério de ferro & 1 \\
\hline desempenho & 1 & blocos compactados & 1 \\
\hline expansão do concreto & 1 & reciclagem & 1 \\
\hline pozolanas & 1 & simulação & 1 \\
\hline escória de aciaria & 1 & pilar & 1 \\
\hline expansão & 1 & temperatura & 1 \\
\hline compostos de lítio & 1 & reações alcalinas & \\
\hline argamassa & 1 & sílica & 1 \\
\hline cinza de casca de arroz & 1 & durabilidade & 1 \\
\hline resíduo de cerâmica vermelha & 1 & modelagem & 1 \\
\hline
\end{tabular}

\section{CONCLUSÕES}

O presente artigo permitiu enumerar as seguintes conclusões:

- O tema possui pesquisas datadas de 1979, demonstrando, assim, que as reações álcali-agregado já eram motivo de problema em regiões da Europa. No Brasil, este tema veio apresentar relevância a partir de acidentes da construção civil datados de 2004. Nesse contexto, entende-se que são necessários mais estudos a respeito das reações álcali-agregado, seja abordando seu mecanismo de ação ou formas de mitigá-la.

- Notou-se que ainda há carência de trabalhos que abordem a modelagem da RAA, seja pelo conhecimento ainda não enraizado da reação ou pela quantidade de variáveis que interferem nesta. Os artigos exploram mais petrografia e novos materiais visando a mitigação da reação.

- A nacionalidade dos periódicos e das pesquisas não apresentou diversidade, identificando-se que a produção científica do tema foi concentrada mais na Europa e América do Sul.

- Vê-se que várias instituições e autores renomados pesquisam sobre as reações álcali-agregado, notadamente sobre as reações álcali-sílica. Ainda que a RAS seja de maior ocorrência nas obras, entende-se que é preciso explorar mais os outros dois tipos por terem grau elevado de gravidade.

- Apesar de, no Brasil, a primeira evidência de RAA ter ocorrido no Nordeste, as produções científicas foram, em sua maioria, desenvolvidas nas regiões Sudeste e Sul, demonstrando que o tema não está disseminado homogeneamente pelas regiões geográficas brasileiras.

\section{AGRADECIMENTOS}

À Universidade Estadual Vale do Acaraú (UVA) e à Universidade Federal do Ceará (UFC).

\section{REFERÊNCIAS}

ASSOCIAÇÃO BRASILEIRA DE NORMAS TÉCNICAS. ABNT NBR 15577-1: Agregados - reatividade álcaliagregado. Parte 1: guia para avaliação da reatividade potencial e medidas preventivas para uso de agregados em concreto. 2 ed. Rio de Janeiro, 2018. 
ENSSLIN, L et al. ProKnow-C: Processo de análise sistêmica. Brasil: processo técnico com patente de registro pendente junto ao INPI, 2010.

FIGUEIRÔA, J. do P.; ANDRADE, T. O ataque da reação álcali-agregado sobre as estruturas de concreto: a descoberta pioneira da ocorrência do problema em fundações de ponte e edifícios na Região Metropolitana do Recife. Recife: Ed. Universitária da UFPE, 2007.

HASPARYK, N. P. Reação álcali-agregado no concreto. In: ISAIA, G. C.(Editor) Concreto: ciência e tecnologia, v. 2, São Paulo: IBRACON, 2011.

LACERDA, R. T.; ENSSLIN, L.; ENSSLIN, S. R. Uma análise bibliométrica da literatura sobre estratégia e avaliação de desempenho. Gestão da Produção, São Carlos, v. 9, n. 1, :5978, nov. 2012.

MASSA CINZENTA. Reação Álcali-Agregado: 60\% das obras não previnem patologia. Disponível em: <https:// https://cimentoitambe.com.br/reacao-alcali-agregado-60-das-obras-nao-previnem-patologia/>. Acesso em: 09 de jan de 2020 .

OLLIVER, J. P.; VICHOT, A. (Ed. tradução) CASCUDO, O.; CARASEK, H. Durabilidade do concreto: bases científicas para a formulação de concretos duráveis de acordo com o ambiente. São Paulo: IBRACON, 2014.

RAO, I. K. Métodos Quantitativos em Biblioteconomia e em Ciência da Informação. Brasília: ABDF, 1986.

SOARES, P. B. et al. Análise bibliométrica da produção científica brasileira sobre Tecnologia de Construção e Edificações na base de dados Web of Science. Ambiente Construído, Porto Alegre, v. 16, n. 1, p. 175-185, jan./mar. 2016.

ZHU, D.et al. A Process for Mining Science \& Technology Documents Database, Illustrate For the Case of Knowledge Discovery and Data Mining. Ciência da Informação, v. 28, n. 1, jan. 1999. 